Original Article

\title{
Shadow Moiré technique for postural assessment: qualitative assessment protocol by intra- and inter-rater evaluation
}

\author{
José Nunes da Silva Filho'), Luiz Alberto Batista, PhD ${ }^{1)}$, Jonas Lírio Gurgel, PhD²), \\ Flávia PORTO, $\mathrm{PhD}^{1)^{*}}$ \\ 1) Institute of Physical Education and Sports, Rio de Janeiro State University: Rua São Francisco \\ Xavier 524, sala 9122F. Bairro Maracanã, Rio de Janeiro, RJ, CEP: 20550-900, Brasil \\ 2) Institute of Physical Education, Fluminense Federal University, Brasil
}

\begin{abstract}
Purpose] This study aimed to develop and validate an assessment tool for Moiré topogram made specifically with the Shadow Moiré technique of the dorsum. [Subjects and Methods] In the analysis of topograms, frontal, sagittal, and transverse planes of individuals' dorsal were considered. Two instructor evaluators analyzed the topograms at different times in the day and on different days. The measurements of intra- and inter- (intra- and interday) reliability were calculated. [Results] Of the three planes analyzed, in all analyses, good (0.61 to 0.80) and/ or excellent (0.81 to 1 ) concordances were observed. [Conclusion] This analysis framework can be recommended to evaluate the topograms obtained with SMT.

Key words: Moiré topography, Posture, Reproducibility of results
\end{abstract}

(This article was submitted Oct. 18, 2016, and was accepted Nov. 14, 2016)

\section{INTRODUCTION}

Currently, radiographic examination is the gold standard for identifying deviations in the posture of the spine, allowing visualization of the patient's vertebrae while standing in addition to measuring the bending angle and segment speeds ${ }^{1)}$.

However, despite its obvious contribution to diagnostic medicine, ionizing radiation inherent to the radiographic examination may cause damage to health. As an example, in less than 65 years after the discovery of X-rays in 1895, 360 deaths were registered among health professionals and patients as a result of exposure to radiation during radiographic recording ${ }^{2}$. Radiation has a cumulative effect, and the younger the patient is who is exposed to it, the greater the damage to the body, which includes modifying genetic material and causing cell death ${ }^{3)}$. The test may be riskier for children because their bodies have increased radiosensitivity, and it is possible that they will accumulate a great deal of exposure to radiation during their lifetimes ${ }^{3,4}$. Such risks make advances in diagnostics essential. The creation and validation of techniques and indirect methods are of particular interest, especially for monitoring the evolution of idiopathic scoliosis in young people, as these conditions produce demand for conducting periodic radiographic examinations using three phase X-rays and the high-speed X-ray ${ }^{5)}$.

The high financial cost is another factor that complicates the periodic use of panoramic radiography of the spine for the patient. This factor has increased examining spinal posture by imaging parts of the spine instead of imaging the entire spine in a single image (panoramic). The need to pay highly trained professionals ${ }^{6}$, and costs for preparing the environment, including shielding walls, light box, screens, cameras, and other items, all contribute to this cost. This reinforces the importance of developing alternative techniques to assess posture that are financially viable and safe for the health of the individual.

Evaluation of body posture is part of the standard practice of various health professionals, such as physical education

*Corresponding author. Flávia Porto (E-mail: flaviaporto30@gmail.com)

(C2017 The Society of Physical Therapy Science. Published by IPEC Inc.

This is an open-access article distributed under the terms of the Creative Commons Attribution Non-Commercial No Derivatives (by-nc-nd) License $<$ http://creativecommons.org/licenses/by-nc-nd/4.0/>. 
teachers, physiotherapists, and doctors. These professionals use assessment of posture to identify postural deviations or monitor the progression of students and patients in realigning their bodies through physical exercise or physical rehabilitation programs. This assessment, even if not performed through X-ray examination, may be useful to provide an indication of various changes in posture.

The Moiré topography (MT) appears to be a viable and complementary alternative to radiographic examination in evaluating trunk posture ${ }^{7,8)}$. It is based on optical phenomena, and Moiré provides a three-dimensional shape analysis of objects from a two-dimensional image ${ }^{8-10)}$. Analysis of the Moiré topograms obtained from the individual's back allows verification of asymmetries and postural unevenness, and can be performed in a manner that is either predominantly qualitative ${ }^{11,12)}$ or quantitative $^{7,13)}$.

One of the techniques employed by TM is the Shadow Moiré technique (SMT). Unlike X-rays, the SMT offers no risk to the health of the individual ${ }^{6)}$ and therefore, patients can be evaluated several times, which is essential for monitoring the realignment of posture. Additionally, its low $\operatorname{cost}^{6,12,14)}$ makes it suitable for use in schools and basic health units. This facilitates diagnosis of suspected postural deviations, even in childhood, aiding the early detection and treatment of such diseases ${ }^{11,15)}$. SMT can also be used in the elderly, which is significant considering the high prevalence of structural postural deviations in these individuals ${ }^{7}$.

This study aimed to develop and validate an assessment tool for Moiré topogram made specifically with the SMT of the dorsum. Despite the advantages of using this technique, there is a great likelihood of mistakes due to fatigue when evaluating a large number of topograms qualitatively ${ }^{10,13}$. Moreover, to date, we have not found a tool that guides the best qualitative assessment of Moiré topograms. The central question of this article is, therefore: is there reliability in the qualitative evaluation of Moiré topograms?

\section{SUBJECTS AND METHODS}

This is a reliability study and therefore aims to measure the consistency of the results when the method is repeated more than once, either by the same person or by different evaluators ${ }^{16,17)}$.

We analyzed 15 topograms obtained from the postural assessment of the spine of 15 professionals in nursing, including nurses and nursing technicians, all employees of a polyclinic in the city of Niterói, RJ. Subjects included three males and 12 females, between 32 and 61 years of age. Data collection occurred in September of 2014. The research procedures followed the relevant guidelines and regulatory standards for research conducted in Brazil with human subjects, under Resolution 466 of December 12, 2012, of the National Council of Health ${ }^{18)}$. The study was approved as No. 679,764/2014 by the Ethics Committee for Institutional Research. At the end of the study, the volunteers were given the results of their assessments.

Two examiners analyzed 15 Moiré topograms. The examiners were previously trained physical education professionals. One qualitative assessment script was used to determine postural deviations in the frontal, sagittal, and transverse planes ${ }^{19)}$.

This script divides the analysis into the following steps:

1) The frontal plane was observed, seeking the following in the order shown:

a) asymmetries of the spine - in this case, the presence of concavity of the right or left sides in the cervical, thoracic, and lumbar spines;

b) alignment of the spine - the alignment of Moire fringes in the three regions of the spinal column describing whether there was a side (left or right) higher than the other, or if they were flattened if symmetrical;

c) asymmetries of the blades - if there was unevenness between the shoulder blades, if a scapula (left or right) was higher than the other, or if they were flattened if symmetrical.

2) In the sagittal plane, asymmetries related to the physiological curvature (lordosis and kyphosis) of three regions of the spine were analyzed.

3) In the transverse plane, the leveling of the shoulder blades was identified through the number of centroids present in the topogram, corresponding to the presence of spinal deformity.

To determine inter-rater reliability (A vs. B), both received topograms and a sheet to report results via e-mail. To determine the stability of intra-rater measure (A vs. A), the examiner received topograms and sheet to report results again after 48 hours from the time of their first assessment. All evaluations were performed in the afternoon between the 1:00 and 6:00 PM.

In both initial and repeated measurements, the two examiners performed the evaluations independently, blind to the allocation of topograms and the result of their fellow examiner. All conditions of assessment, data tabulation, and statistical analyses were guaranteed by the present study coordinator.

A Kappa Cohen agreement test, with intra- and inter-raters on intraday and interday tests and retests was conducted, using a mixed effects model with two inputs. For the analyses, the established statistical significance was set at $\mathrm{p} \leq 0: 05$, using the statistical package (SPSS 20.0, SPSS Inc., Chicago, IL, USA).

To anthropometric assessment, height, body mass, abdominal perimetry, and hip measurements were taken, and body mass index (BMI) and waist-hip ratio (WHR) were calculated according to the International Standards recommendations for Anthropometric Assessment ${ }^{20}$. To perform this, a portable stadiometer (EST 22 Cachoeira do Sul, RS, Brazil) with a maximum capacity of $2 \mathrm{~m}$ and a minimum capacity of $0.3 \mathrm{~m}$, with an accuracy of $0.001 \mathrm{~m}$, was used, as well as a mechanical scale (Filizola, mod 31, Osasco, SP, Brazil) with an accuracy of $100 \mathrm{~g}$ and a maximum capacity of $150 \mathrm{~kg}$ and anthropometric tape 


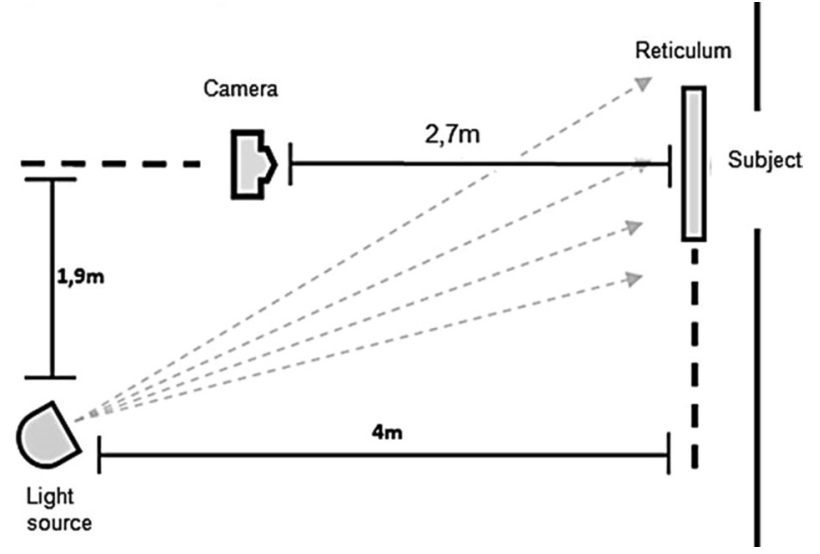

Fig. 1. The method of postural evaluation with SMT

Table 1. Characteristics of individuals participating in the research $(n=15)$

\begin{tabular}{lccc}
\hline Variable & Average (SD) & Min \& Max & md (Q1 \& Q3) \\
\hline Age (years) & $47 \pm 9.5$ & $32-61$ & $50(38-55)$ \\
Weight $(\mathrm{kg})$ & $75.3 \pm 15.3$ & $60-95$ & $67(59.5-79)$ \\
Height $(\mathrm{m})$ & $1.6 \pm 0.1$ & $1.51-1.72$ & $1.60(1.55-1.65)$ \\
BMI $\left(\mathrm{kg} / \mathrm{m}^{2}\right)$ & $26.6 \pm 5.1$ & $17.9-34.4$ & $25.8(25.8-31.1)$ \\
\hline
\end{tabular}

MC: body mass; SD: standard deviation; Min: Minimum; Max Maximum; md: Median; Q1 (1st quartile); Q3 (3rd quartile); BMI: body mass index

Table 2. Qualitative assessment of the reliability of topograms obtained with SMT.

\begin{tabular}{|c|c|c|}
\hline \multirow{2}{*}{$\begin{array}{l}\text { Deviation by planes and } \\
\text { regions of the spine }\end{array}$} & \multicolumn{2}{|c|}{ Kappa } \\
\hline & Intra & Inter \\
\hline \multicolumn{3}{|l|}{ Front plane } \\
\hline Asymmetries of VC & $0.82^{\mathrm{a}^{*}}$ & $0.81^{\mathrm{a}^{*}}$ \\
\hline Cervical region & $0.71^{b^{*}}$ & $0.69^{b^{*}}$ \\
\hline Thoracic region & $0.88^{\mathrm{a}^{*}}$ & $0.89^{\mathrm{a}^{*}}$ \\
\hline \multicolumn{3}{|l|}{ Lumbar region } \\
\hline Front plane & $1.00^{\mathrm{a}^{*}}$ & $1.00^{\mathrm{a}^{*}}$ \\
\hline Alignment VC & $1.00^{\mathrm{a}^{*}}$ & $1.00^{\mathrm{a}^{*}}$ \\
\hline Cervical region & $0.76^{\mathrm{b}^{*}}$ & $0.77^{b^{*}}$ \\
\hline \multicolumn{3}{|l|}{ Thoracic region } \\
\hline Lumbar region & $1.00^{\mathrm{a}^{*}}$ & $0.63^{\mathrm{b}^{*}}$ \\
\hline \multicolumn{3}{|l|}{ Front plane } \\
\hline Unevenness of scapulas & $0.76^{\mathrm{b}^{*}}$ & $1.00^{\mathrm{a}^{*}}$ \\
\hline Flush or unlevel & $0.66^{\mathrm{b}^{*}}$ & $0.85^{\mathrm{a}^{*}}$ \\
\hline Sagittal plane & $0.72^{\mathrm{b}^{*}}$ & $0.90^{\mathrm{a}^{*}}$ \\
\hline \multicolumn{3}{|l|}{ Asymmetries of VC } \\
\hline Cervical region & $1.00^{\mathrm{a}^{*}}$ & $1.00^{\mathrm{a}^{*}}$ \\
\hline \multicolumn{3}{|c|}{ 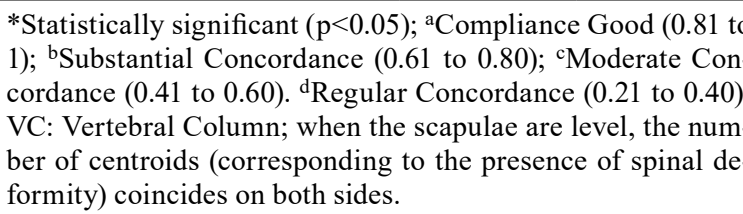 } \\
\hline
\end{tabular}

(CESCORF Ltda., Porto Alegre, RS, Brazil). BMI calculation was based on the World Health Organization's standards ${ }^{21}$ for adults over 18 years old.

The method for obtaining the Moiré topograms followed the proposals of previous studies 7 , 14, 22). The following equipment was used to obtain the topograms: a camera (Sony Cyber-shot model, 14.1MP, Psc model W350, Manaus, AM, Brazil) fixed to a tripod, a light source (100 W, Bellalux, Osasco, SP, Brazil), a grid (lattice) constructed with nylon yarn (Grilon 210/36, 1:35 mm, $200 \mathrm{~g}$, São Paulo, SP, Brazil) with a period of $1 \mathrm{~mm}$ and painted with opaque black ink. In a darkened room, the volunteer remained standing, shirtless and barefoot, his spine to the reticle as the light fell obliquely on his back. A photo was obtained in a plane perpendicular to the grid. All samples were taken by a professional in physical education. Figure 1 shows the experiment setup used for capturing Moiré topograms.

At the end of the evaluations, seeking to ensure the ethical principles of research involving human subjects and volunteers, clinical information of the results obtained in the evaluations was made available to the test subjects.

\section{RESULTS}

Table 1 shows the characteristics of the volunteers assessed.

The intra- and interreliability related to postural evaluations is shown in Table 2, whose concordance measurements were obtained using Cohen's kappa test ${ }^{23}$.

\section{DISCUSSION}

It is concluded that the SMT analysis framework in this study showed an inter- and intra-reliability considered to be between good and/or excellent. Thus, it may be considered reliable and can be recommended for qualitative evaluations of the topograms obtained with SMT for body posture of the back.

In health literature, there is currently an increase of studies conducted to verify and evaluate scales, questionnaires and other qualitative research tools ${ }^{24)}$. To perform high-quality research, it is important that procedures and instruments be reliable to decrease the risk of bias in outcomes ${ }^{25}$. This adds credibility and legitimacy to the study ${ }^{26}$.

Confirming the reliability of a measurement is important so that results of a technique can be considered accurate and consistent between times and locations and therefore, the phenomenon being studied may have better follow through values 
between surveys ${ }^{24)}$.

Concerning the reliability of posture evaluation, some factors give reason to question the veracity of the findings, such as the assessment being carried out essentially by observation ${ }^{27}$. This is because it is an assessment with very high subjective content, and therefore, tools to assess quality control must accompany it. Several factors may be involved in the evaluation of postural deviations, such as anthropometric factors and the positioning of the feet of the individual during the evaluation ${ }^{28)}$.

The predominantly qualitative assessments require greater control over variables, making it necessary to include criteria and procedures to reduce limitations commonly seen in postural assessments that can compromise the description of the phenomenon studied.

Thus, in the present study, we sought to mitigate these problems by adequately controlling possible variables, providing instructions to volunteers beforehand such as guiding them to remain in a comfortable position. In procedures that use photography, it is common for the volunteer - at that moment - to try and stay in a more upright posture, thus changing the outcome of the analysis. Furthermore, it was of concern to not force them to position themselves with their feet in a certain way so that there was no forced change in their posture ${ }^{27)}$.

The use of topograms for evaluation of body posture can be considered a positive aspect of our study, since according to Iunes et al. ${ }^{29)}$ and Sacco et al. ${ }^{30)}$, the use of photos in the assessment of posture, as it becomes the most reliable data, ends up facilitating the analysis and storage of data, saves space and time, and allows access to files, which are important factors for conducting new research.

The topograms analyzed in this study were drawn from 15 nurses working in a polyclinic in the city of Niterói, RJ. It is known that for purposes of analyzing the reliability of this technique, the posture of these professionals did not significantly improve. It is suggested that further studies be conducted with individuals of different characteristics, such as age, work activity, and others factors because the functional demands of people throughout life interfere with an individual's body posture. Furthermore, it is possible that other deformities present in these subjects are less sensitive to the proposed method.

Although Takasaki ${ }^{31)}$ has proposed SMT for clinical examinations of body posture, to date, we have not found any tool to guide the best qualitative assessment of Moire topograms. Therefore, the main aim of the present study is the verification of the reliability of measurements made using a proposed Moiré topogram qualitative assessment tool. It is noteworthy that, although studies have not been found that have investigated the reliability of this method, the reason for this appears not to be due to an opinion of scientific irrelevance, but rather the lack of knowledge about the technique by researchers in general. The MT has many advantages: it is not invasive, does not require much training of evaluators ${ }^{8)}$, has a low cost, and requires little time to obtain images ${ }^{6,8)}$.

The findings in this study could show that the use of Moiré topograms as a qualitative assessment tool has proved fairly reliable in both intra- and inter-rater assessments for all studied postural deviations.

Although the results presented reliable agreements at all levels, it was noted that the consistency of opinions regarding asymmetries in the sagittal plane was slightly lower than that of opinions regarding other planes. This outcome is consistent with other studies that, even using other evaluation tools of the spine, also found little reliability in measures relating to spinal curvatures in the sagittal plane ${ }^{29,32,33)}$. This lower reliability of measurements of the spine in the sagittal plane, according to Teo and $\mathrm{Ng}^{34)}$, can be justified as most indirect methods address a one-dimensional evaluation and the changes of the spine are usually three-dimensional.

In the present study, it is believed that although the Moiré topograms make a three-dimensional analysis of the dorsum possible ${ }^{8)}$, the evaluator may find it difficult to view asymmetries in the sagittal plane, due to lower sharpness of fringes, especially in the cervical and lumbar regions, which could justify considering the measurements of the sagittal plane less reliable when compared to the measures of other planes.

Also, a detail was noticed about the instrument used that may be important for clinical practice. It was noted that the analyses performed in the sagittal plane, especially in the cervical and lumbar regions, end up being a limiting factor evaluation with the SMT. Even with a reliable intra- and inter-rater agreement, it was found that in most analyzed topograms, both evaluators marked the option "could not see" on the reporting sheet.

For evaluations of topograms of the cervical region, there was a high presence of option "could not be seen"- $73.3 \%$ of topograms $(n=11)$ were marked as such by both evaluators (A vs. B), and summed between both evaluators, $80 \%$ of topograms $(\mathrm{n}=12)$ were marked as such by the same evaluator (A vs. A). In the lumbar region, although showing a lesser percentage, there was also a considerable presence of the option "could not see", yielding a total of $47 \%$ ( $n=7$ ) between evaluators (A vs. B) and 40\% $(n=6)$ in intra-rater assessments. The inability to see the fringes of Moiré by the evaluators is thought to be due to a mistake made by the evaluator in obtaining topograms, the deformities presented by the subjects, or even limitations of the method.

Moiré techniques have proved in other studies to be more effective than simply viewing posture evaluation to verify asymmetries of the cervical and lumbar spine ${ }^{6,32)}$. Although SMT is also predominantly qualitative, in this study, there was a strict control of methodological variables, which may explain the higher levels of reliability that were found.

The technique analyzed in this study is reliable; it is suggested that the dissemination and use of SMT can test trunk posture without the need to expose individuals to ionizing radiation and when they need information on the bone quality of the individual. As more than $90 \%$ examiners use visual estimation as a tool to assess the posture of the spine ${ }^{32)}$, the ease and reliability of SMT, as shown here, can be an incentive to make it a substitute for other methods for this kind of evaluation. 


\section{REFERENCES}

1) Malfair D, Flemming AK, Dvorak MF, et al.: Radiographic evaluation of scoliosis review. AJR, 2010, 19410: 8-22. [CrossRef]

2) Navarro MV, Leite HJ, Alexandrino J C, et al.: Controle de riscos à saúde em radiodiagnóstico: uma perspectiva histórica. História, Ciências, Saúde-Manguinhos. Casa Oswaldo Cruz, 2008, 15: 1039-1047.

3) Caruncho MV: Os efeitos da radiação diagnóstica. Rev Bras Med Fam Comunidade, 2011, 6: 116-117. [CrossRef]

4) Brent RL: Carcinogenic risks of prenatal ionizing radiation. Semin Fetal Neonatal Med, 2014, 19: 203-213. [Medline] [CrossRef]

5) Knott P, Pappo E, Cameron M, et al.: SOSORT 2012 consensus paper: reducing x-ray exposure in pediatric patients with scoliosis. Scoliosis, 2014, 9: 4. [Medline] [CrossRef]

6) Yeras AM, Peña RG, Junco R: Moiré topography: alternative technique in health care. Opt Lasers Eng, 2003, 40: 105-116. [CrossRef]

7) Porto F, Gurgel JL, Russomano T, et al.: Shadow Moire Technique to measure deformity of the trunk surface in the elderly: a population-based study. In: Bessette A, Rousseau CM (eds.) In: Scoliosis: causes, symptoms and treatment. New York: Nova Science Publishers (Nova Biomedical), 2012, pp 73-90.

8) Porto F, Gurgel JL, Russomano T, et al.: Moiré topography: characteristics and clinical application. Gait Posture, 2010, 32: 422-424. [Medline] [CrossRef]

9) Drerup B: A procedure for the numerical analysis of Moiré topograms. Photogramm, 1981, 36: 41-49. [CrossRef]

10) Kim HS, Ishikawa S, Ohtsuka Y, et al.: Automatic scoliosis detection based on local centroids evaluation on moiré topographic images of human backs. IEEE Trans Med Imaging, 2001, 20: 1314-1320. [Medline] [CrossRef]

11) Adler NS, Csongradi J, Bleck EE: School screening for scoliosis. One experience in California using clinical examination and moiré photography. West J Med, 1984, 141: 631-633. [Medline]

12) Batouche M, Benlamri R: A computer vision system for diagnosing scoliosis. IEEE Int Conf Pervasive Comput Commun, Orlando: 1994, pp $2623-2628$.

13) Kim H, Kooi Tan J, Ishikawa S, et al.: Automatic judgment of spinal deformity based on back propagation on neural network. IJICIC, 2006, 2: $1271-1279$.

14) Hertz H, Russomano T, Porto F, et al.: Desenvolvimento da Técnica de Moiré de Sombra como alternativa de baixo custo para análise postural. Sci Med (Porto Alegre), 2005, 15: 235-242.

15) Berntsen E, Risgaard-Petersen B: [Screening of school children for scoliosis. Examination of the back with moiré topography and controlled forward bending test]. Ugeskr Laeger, 1981, 143: 3373-3377. [Medline]

16) Atkinson G, Nevill AM: Statistical methods for assessing measurement error (reliability) in variables relevant to sports medicine. Sports Med, 1998, 26: 217-238. [Medline] [CrossRef]

17) Thomas JR, Nelson JK, Silverman SJ: Métodos de pesquisa em atividade física, 6th ed. Porto Alegre: Artmed, 2012 , pp 478.

18) Brasil: Resolução 466, de 12 de dezembro de 2012. Trata de pesquisas e testes em seres humanos. Diário Oficial da União, 2012.

19) Porto F: Guia de avaliação postural com a técnica de Moiré de sombra, Rio de Janeiro: 2012, pp 1-3.

20) Marfell-Jones MJ, Stewart AD, de Ridder JH: International standards for anthropometric assessment. South Africa: Potchefstroom, 2012.

21) World Health Organization: Obesity: preventing and managing the global epidemic. Report of a WHO consultation. World Health Organ Tech Rep Ser, 2000, 894: i-xii, 1-253. [Medline]

22) Hertz HR: Construção a calibração da técnica de Moiré de sombra para análise postural (THES), Porto Alegre: Pontifícia Universidade Católica do Rio Grande do Sul, 2005.

23) Cohen J: A coefficient of agreement for nominal scales. Educ Psychol Meas SAGE Publ, 1960, 20: 37-46. [CrossRef]

24) Alexandre NMC, Coluci MZO: Validade de conteúdo nos processos de construção e adaptação de instrumentos de medidas. Cien Saude Colet, ABRASCO -Associação Brasileira de Saúde Coletiva, 2011, 16: 3061-3068.

25) Raymundo VP: Construção e validação de instrumentos: um desafio para a psicolinguística. 2009, 44: 86-93.

26) Medeiros R, Júnior M, Pinto D, et al.: Pasquali’s model of content validation in the nursing researches. Rev Enferm Ref, Escola Superior de Enfermagem de Coimbra -Unidade de Investigação em Ciências da Saúde -Enfermagem, 2015, IV Série: 127-135.

27) Ferreira EA: Postura e controle postural: desenvolvimento e aplicação de método quantitativo de avaliação postural, São Paulo: Biblioteca Digital de Teses e Dissertações da Universidade de São Paulo, 2005, p 114.

28) Chiari L, Rocchi L, Cappello A: Stabilometric parameters are affected by anthropometry and foot placement. Clin Biomech (Bristol, Avon), 2002, 17: 666-677. [Medline] [CrossRef]

29) Iunes DH, Castro FA, Salgado HS, et al.: Confiabilidade intra e interexaminadores e repetibilidade da avaliação postural pela fotogrametria. Avaliação Postural pela Fotogram 327 Rev bras fisioter, 2005, 9: 327-334.

30) Sacco I, Alibert S, Queiroz B, et al.: Confiabilidade da fotogrametria em relação a goniometria para avaliação postural de membros inferiores. Rev Bras Fisioter. Braz J Phys Ther, 2007, 11: 411-417. [CrossRef]

31) Takasaki H: Moiré topography. Appl Opt, 1970, 9: 1467-1472. [Medline] [CrossRef]

32) Fedorak C, Ashworth N, Marshall J, et al.: Reliability of the visual assessment of cervical and lumbar lordosis: how good are we? Spine, 2003, 28: 1857-1859. [Medline] [CrossRef]

33) Normand MC, Harrison DE, Cailliet R, et al.: Reliability and measurement error of the BioTonix video posture evaluation system-Part I: Inanimate objects. J Manipulative Physiol Ther, 2002, 25: 246-250. [Medline] [CrossRef]

34) Teo EC, Ng HW: Evaluation of the role of ligaments, facets and disc nucleus in lower cervical spine under compression and sagittal moments using finite element method. Med Eng Phys, 2001, 23: 155-164. [Medline] [CrossRef] 